\title{
Endovascular Management of Acute Superior Mesenteric Artery Thrombosis in a Delayed Setting
}

\author{
Saxena A. ${ }^{{ }^{*}}$, Srivastava . $^{2}$ \\ DOI: https://doi.org/10.17511/ijmrr.2019.i02.10
}

1* Agamya Saxena, Noble Hospital, Bhopal, Madhya Pradesh, India.

2 Prashant Srivastava, Noble Hospital, Bhopal, Madhya Pradesh, India.

Acute mesenteric ischemia [AMI] is a life-threatening situation, the diagnosis of which is often missed in early stages. Late diagnosis often precludes endovascular management as the primary treatment. The authors here present a case of seven days history of acute mesenteric ischemia in a young female, who not just benefited from endovascular management, but also a major surgical intervention was avoided and was discharged from the hospital uneventfully. The decision to consider a patient for endovascular management in a late stage, requires a good interdisciplinary communication and successful outcome in such a scenario is rarely achieved.

Keywords: Acute mesenteric ischemia, Thrombosis, Acute Superior Mesenteric Artery

Corresponding Author

Agamya Saxena, Noble Hospital, Bhopal, Madhya Pradesh, India.

Email: agamya.saxena@gmail.com
How to Cite this Article

Saxena A, Srivastava P. Endovascular Management of Acute Superior Mesenteric Artery Thrombosis in a Delayed Setting. Int J Med Res Rev. 2019;7(2):112114.

Available From

https://ijmrr.medresearch.in/index.php/ijmrr/article/ view/1049
To Browse

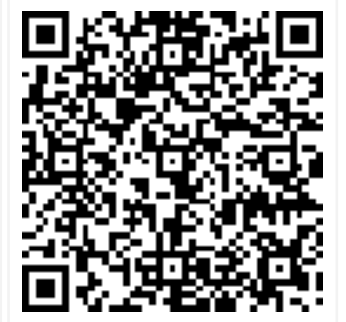

Manuscript Received 2019-03-28

Conflict of Interest No
Review Round 1 2019-04-07

Funding
Review Round 2 2019-04-15

Ethical Approval Yes
Review Round 3

Plagiarism X-checker $4 \%$
Accepted 2019-04-19

Note 


\section{Introduction}

Acute Superior Mesenteric Artery [SMA] thrombosis is an uncommon, but life-threatening emergency, carrying a high rate of morbidity and mortality. It constitutes about $0.1 \%$ of all hospital admissions. Despite, all advancements in its diagnosis and treatment, it still carries an indoor mortality rate of $59-93 \%[1]$.

Endovascular thrombolysis, thrombo-aspiration, angioplasty and stenting of mesenteric vasculature are established management strategies, but only when the patient presents in an early stage. Late cases are usually treated with the more invasive option of surgical resection of gangrenous bowel, which itself carries high morbidity and mortality rates.

\section{Case Report}

A 36 years old female presented with sudden onset, vague, non-localised, abdominal pain and distention. Other than type 2diabetes, there was no significant medical or surgical history. Also, there was no previous history of any such abdominal pain.

For initial four days, the patient got admitted at some other hospital, where her serial ultrasound scans were reported as normal. Hence, she was treated on conservative grounds.

The patient was then shifted to our hospital after seven days of onset of symptoms. The Contrast Enhanced Computerized Tomography [CECT] of abdomen confirmed complete short-segment thrombosis of celiac trunk [Fig.1], and partial shortsegment thrombosis of SMA [Fig.2].

The Inferior Mesenteric Artery [IMA] and its branches were patent. Her White Blood Cell [WBC] count was 29000 cells/cu $\mathrm{mm}$, with infrequent spikes of high-grade fever and progressive abdominal distention.

She was immediately started on continuous intravenous heparin infusion. With now a history of 7 days duration, the possibility of bowel gangrene was high, and the need for open surgery was imminent. Still, due to young age of patient, and an otherwise good general condition, a decision of endovascular management was made.

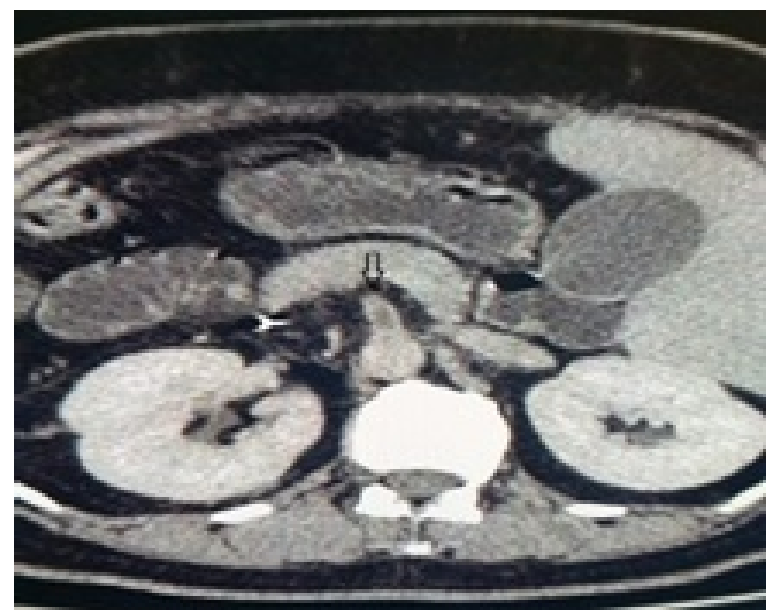

Figure 1: CECT abdomen axial scan depicting short-segment thrombosis of the celiac trunk [arrow]

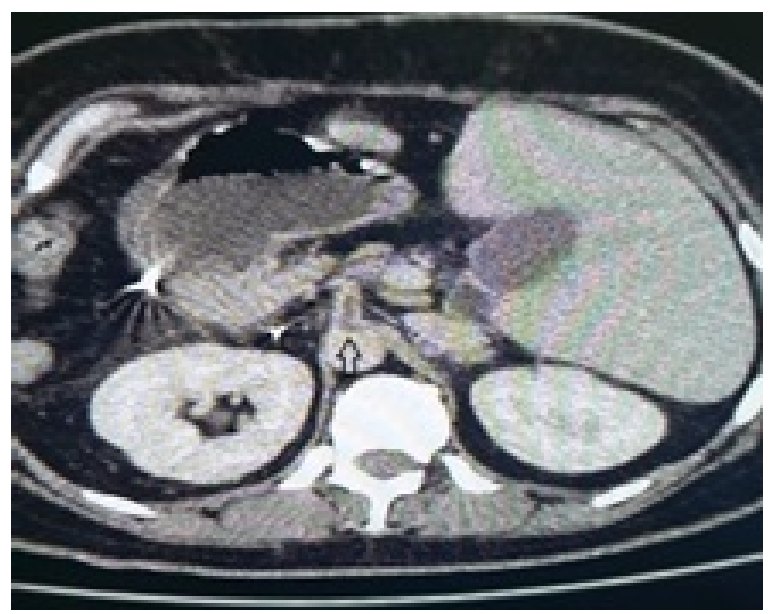

Figure 2: CECT abdomen axial scan depicting short-segment thrombosis of the SMA [arrow]

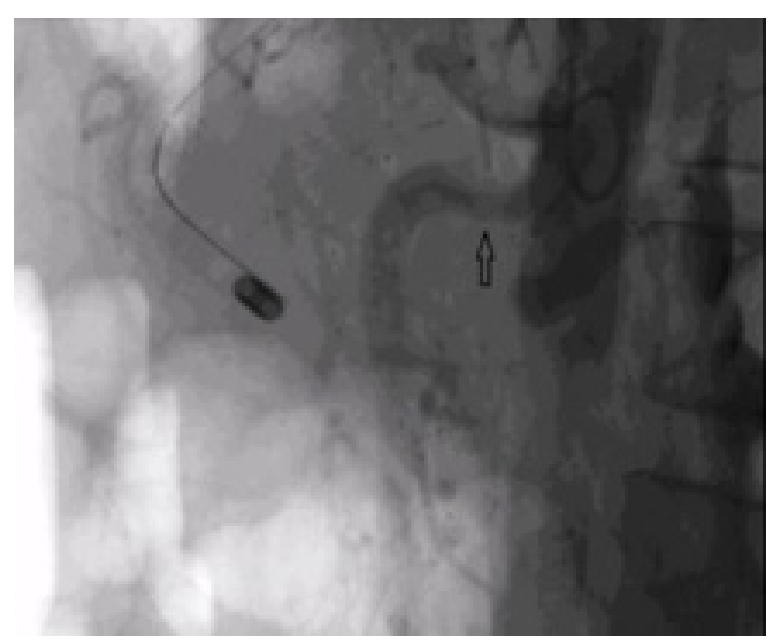

Figure 3: Digital substraction angiogram showing residual stenosis in SMA [arrow] 


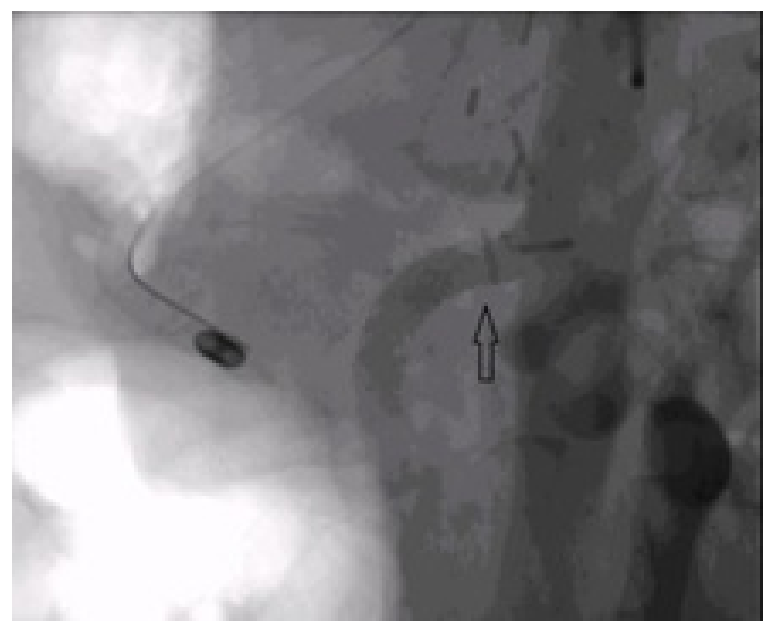

Figure 4: Satisfactory post-stenting flow achieved in SMA [arrow]

A left brachial artery access was taken with $6 \mathrm{~F}$ sheath. Abdominal aortogram was performed which reconfirmed the findings of CECT scan. The $5 \mathrm{~F}$ cobra catheter was placed in proximal SMA. 4400units/Kg body weight of Urokinase was slowly injected as bolus, over 10 minutes. The catheter was secured in place and urokinase was further administered through the catheter at a rate of $4400 \mathrm{units} / \mathrm{Kg}$ body $\mathrm{wt} / \mathrm{hr}$ for next 15 hours. Weight-adjusted heparin was also administered via side arm of the sheath. The course during thrombolysis was uneventful. After 15 hours of thrombolysis, patient's pain subsided near completely and WBC count dropped to 16000 cells/cu mm. Check aortogram was performed, which revealed near-complete recanalisation of celiac trunk, and partial [approx. $30 \%$ ] recanalisation of SMA [Fig. 3]. Owing to significant residual stenosis, a balloon-mounted, nitinol stent of size $8 \times 36 \mathrm{~mm}$ [Valeo, BD, NJ, USA] was placed in proximal SMA. Satisfactory poststenting flow was achieved [Fig. 4]. Heparin infusion was continued through sheath for next 12 hours, and dual antiplatlet therapy was initiated. She was gradually started on oral feeds, with normal bowel movements. As such, she did not require any further surgical intervention, and was discharged uneventfully 10 days after the procedure.

\section{Discussion}

The causes of acute mesenteric ischemia include arterial embolus, which occurs most frequently (40\%-50\%), arterial thrombosis, venous obstruction and nonobstructive causes. Patients present with severe abdominal pain that is initially out of proportion to any physical findings.
The diagnosis should be considered in patients with the following risk factors: age older than 60 years, previous history of vascular disease or valvular heart disease, cardiac arrhythmia, emboli, hypotension, recent heart failure, or hypercoagulability. In our experience, duplex ultrasonography of the abdomen is not an appropriate tool for suspected AMI. Computed tomographic angiography (CTA) is the current best imaging tool for diagnosing AMI. Among all visceral arteries, the SMA is the most susceptible to emboli $(90 \%)$ because of its acute angle of origin with respect to the aorta and high blood flow. Because of the caudal orientation of the SMA, a brachial access can be useful to cannulate the SMA. If a femoral access is used, stiff guidewires are required to provide support to aid passage of catheters into the SMA.

Reports of successful use of several different thrombolytic agents, using a variety of methods of administration, have been published: streptokinase [2], urokinase [3], recombinant tissue plasminogen activator (rtPA) [4], and combinations of thrombolytic agents such as streptokinase and rtPA [5].

Recanalization of an occluded segment may be obtained with an angled 0.035-inch hydrophilic guidewire after a femoral or brachial approach. For proximal lesions, balloon-mounted stents are preferable owing to their more precise delivery system. For more distal lesions, self-expanding stents can also be used.

There is often a tendency to take patients with peritonitis straight to the operating room, without performing angiography.

However, if angiography is rapidly available, it can help identify those patients who may require embolectomy or vascular reconstruction, but it also allows transcatheter treatment of vasospasm in the perioperative period. In patients with signs of peritoneal irritation, percutaneous treatment versus surgery is very controversial.

Complications of percutaneous thrombolysis include bleeding at the puncture site, distal embolization, post-revascularization syndrome, and catheter thrombosis, especially with urokinase, which can be prevented by adjunctive heparinization. The leading complication of angioplasty is risk of embolization. Subsequent thrombolysis is believed to be effective in those cases [6]. 


\section{Conclusion}

The above case depicts the importance of "bowelsalvage" attitude rather than a "bowel-sacrifice" one. In selected young patients, with a satisfactory general condition, and after a thorough interdisciplinary communication; a decision for endovascular treatment can be taken even in a delayed presentation of acute mesenteric ischemia.

\section{Reference}

01. Romano N, Prosperi V, Basili G, et al. Acute thrombosis of the superior mesenteric artery in a 39-year-old woman with protein-S deficiencya case report. J Med Case Rep. 2011 Jan $18 ; 5 ; 17$.

doi: $10.1186 / 1752-1947-5-17$ [Crossref]

02. McBride KD, Gaines PA. Thrombolysis of a partially occluding superior mesenteric artery thromboembolus by infusion of streptokinase. Cardiovasc Intervent Radiol. 1994;17;164-166. [Crossref]

03. Wang G, Lu W, Xia Q, et al. Superior mesenteric arterial embolism- a retrospective study of local thrombolytic treatment with urokinase in West China. Int J Clin Pract. 2003;57;588-591.

[Crossref]

04. Boyer L, Delorme JM, Alexandre M, et al. Local fibrinolysis for superior mesenteric artery thromboembolism. Cardiovasc Intervent Radiol. $1994 ; 17 ; 214-216$.

[Crossref]

05. Nathan $N$, Wintringer $P$, Bregeon $Y$, et al. Intraarterial thrombolysis of acute mesenteric ischemia. Ann Fr Anesth Reanim. 1995;14(1)33-

6.

[Crossref]

06. Wakabayashi $H$, ShiodeT, Kurose $M$, et al. Emergent treatment of acute embolic superior mesenteric ischemia with combination of thrombolysis and angioplasty- report of two cases. Cardiovasc Intervent Radiol. 2004;27;389-393.

[Crossref] 